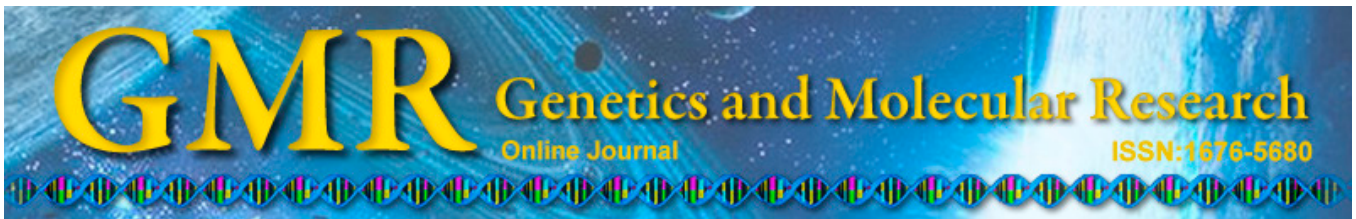

\title{
IL-6-174G/C and IL-6-572C/G polymorphisms are associated with increased risk of coronary artery disease
}

\author{
L. Li ${ }^{1}$, E. Li ${ }^{1}$, L.H. Zhang ${ }^{1}$, L.G. Jian ${ }^{1}$, H.P. Liu' ${ }^{2}$ and T. Wang ${ }^{3}$ \\ ${ }^{1}$ Department of Cardiovascular Internal Medicine, \\ The Second Affiliated Hospital of Zhengzhou University, Zhengzhou, \\ Henan, China \\ ${ }^{2}$ Department of Ultrasonic Medicine, \\ The First Affiliated Hospital of Henan College of Traditional Chinese Medicine, \\ Zhengzhou, Henan, China \\ ${ }^{3}$ Department of Gerontology, \\ The Second Affiliated Hospital of Zhengzhou University, Zhengzhou, \\ Henan, China \\ Corresponding author: T. Wang \\ E-mail: wangtao_sah@163.com \\ Genet. Mol. Res. 14 (3): 8451-8457 (2015) \\ Received November 25, 2014 \\ Accepted February 27, 2015 \\ Published July 28, 2015 \\ DOI http://dx.doi.org/10.4238/2015.July.28.12
}

\begin{abstract}
We conducted this case-control study to investigate the genetic role of IL- $1 \beta+3954 \mathrm{C} / \mathrm{T}$, IL-6-174G/C, IL-6-572C/G, IL-10$1082 \mathrm{~A} / \mathrm{G}$, and IL-10-819C/T in the development of coronary artery disease (CAD) in a Chinese population. Polymorphisms IL-1 $\beta+3954 \mathrm{C} / \mathrm{T}$, IL-6-174G/C, IL-6-572C/G, IL-10-1082A/G, and IL-10-819C/T were determined by polymerase chain reaction restriction fragment length polymorphism assay. The CAD patients were more likely to be cigarette smokers, have a history of hypertension, have a higher value of total cholesterol, triglycerides, and low-density lipoprotein cholesterol, and have a lower value of high-density lipoprotein cholesterol. Conditional logistic regression analyses showed that the CC genotype of IL-6-
\end{abstract}


$174 \mathrm{G} / \mathrm{C}$ was significantly associated with increased risk of CAD [odds ratio $(\mathrm{OR})=2.99,95 \%$ confidence interval $(95 \% \mathrm{CI})=1.56-6.00]$. Moreover, the GG genotype of IL-6-572C/G was correlated with increased risk of $\mathrm{CAD}(\mathrm{OR}=1.99,95 \% \mathrm{CI}=1.25-3.19)$. We found that IL-6-174G/C and IL-6-572C/G gene polymorphisms are associated with an increased risk of CAD.

Key words: Interleukin factor; IL-6; Polymorphisms;

Coronary artery disease

\section{INTRODUCTION}

Coronary artery disease (CAD) is complex and is the leading cause of mortality and morbidity worldwide. It is well known that CAD has multiple causes including environmental and genetic factors (He et al., 2005; Roger et al., 2012). Recently, several studies have indicated that genetic polymorphisms, including those of the MEF2A, CRP, LGALS2, GP78, and MMP-9 genes, are associated with increased risk of CAD (Cha et al., 2014; Foroughmand et al., 2014; Ghaffari et al., 2014; Lian et al., 2014; Opstad et al., 2014).

Previous studies have indicated that inflammation plays an important role in the development of CAD (Hansson, 2005). One animal experimental study has shown that several cytokines play a key role in the development of CAD (Kleemann et al., 2008). Several previous epidemiology studies have shown that polymorphisms in several cytokines, including interleukin-6 (IL-6), IL-16, IL-17, IL-18, and IL-23, are involved in the pathogenesis of CAD (Zhang et al., 2011; Huang et al., 2013; Opstad et al., 2011, 2013; Galimudi et al., 2014; He et al., 2014; Zhang et al., 2014). However, the results of these studies are inconsistent.

Two recent studies have shown that response to inflammatory signaling is associated with the development of CAD (Hansson, 2005; Harismendy et al., 2011). Epidemiologic studies have demonstrated that heritability of the pro-inflammatory state can modulate the susceptibility of CAD (McPherson and Davies, 2012; CARDIoGRAMplusC4D Consortium et al., 2013). Owing to the biological and pathological mechanism of cytokines, we conducted this case-control study to investigate the genetic role of IL-1 $\beta+3954 \mathrm{C} / \mathrm{T}$, IL-6-174G/C, IL-6-572C/G, IL-10$1082 \mathrm{~A} / \mathrm{G}$, and IL-10-819C/T in the development of CAD in a Chinese population.

\section{MATERIAL AND METHODS}

\section{Study population}

A total of 365 patients from the Second Affiliated Hospital of Zhengzhou University were included in our study. Patients were diagnosed either by their symptoms or by the results of electrocardiography. The symptoms were defined as chest pain at rest or during exertion. Using the results of electrocardiography, those who had obstructive lesions of more than $50 \%$ in one or more coronary arteries were considered to have CAD. Patients who had a history of cardiovascular disease, autoimmune disease, severe kidney or liver disease, tumors, or congenital heart disease were excluded from our study.

After selecting each case, we also selected an age- and gender-matched control from individuals who sought a health examination in the health-check center of our hospital. Ulti- 
mately, a total of 365 controls were recruited for our study. Control subjects who had a history of CAD or cardiovascular disease, autoimmune disease, congenital heart disease, severe kidney or liver disease, or tumors were excluded from the study. Written informed consent was obtained from all patients and controls, and the study was approved by the Ethics Committee of the Second Affiliated Hospital of Zhengzhou University.

Baseline characteristics of all of the patients and controls were obtained using a selfdesigned questionnaire and medical records. Data on gender, age, body mass index, alcohol consumption, tobacco consumption, and hypertension were collected from the self-designed questionnaire. Total cholesterol, triglycerides, low-density lipoprotein cholesterol (LDL-C), and high-density lipoprotein cholesterol (HDL-C) levels were determined by blood biochemistry.

\section{Blood samples and genotyping}

For DNA extraction, approximately $5 \mathrm{~mL}$ peripheral blood was obtained from each subject and stored at $-20^{\circ} \mathrm{C}$ in anticoagulant until required. Genomic DNA was isolated from peripheral blood, extracted using a TIANamp Blood DNA Kit (Tiangen Biotech, Beijing, China), and the DNA was dissolved in water, according to manufacturer instructions.

For single nucleotide polymorphism genotyping, the genotypes of IL- $1 \beta+3954 \mathrm{C} / \mathrm{T}$, IL-6-174G/C, IL-6-572C/G, IL-10-1082A/G, and IL-10-819C/T were determined by polymerase chain reaction restriction fragment length polymorphism (PCR-RFLP) assay. Probes and primers for the PCR-RFLP assay were designed using the Primer 5.0 software (PREMIER Biosoft, Palo Alto, CA, USA). The PCR regimen was as follows: one initial denaturation step for $5 \mathrm{~min}$ at $94^{\circ} \mathrm{C}$, followed by 35 denaturation cycles of $45 \mathrm{~s}$ at $94^{\circ} \mathrm{C}, 60 \mathrm{~s}$ of annealing at $62^{\circ} \mathrm{C}, 60 \mathrm{~s}$ of extension at $72^{\circ} \mathrm{C}$, and a final extension at $72^{\circ} \mathrm{C}$ for $10 \mathrm{~min}$. For quality control, genotyping was repeated in $20 \%$ of samples to check for accuracy.

\section{Statistical analysis}

Continuous variables are reported as means \pm standard deviation and were analyzed by the Student $t$-test. Categorical variables, shown as N (\%), were analyzed by the $\chi^{2}$-test. The $\chi^{2}$-test was performed to verify whether the genotype distributions were in Hardy-Weinberg equilibrium for all the single nucleotide polymorphisms. The associations between the CAD and control groups were assessed using conditional logistic regression, and the results are expressed using odds ratios (ORs) and their $95 \%$ confidence intervals $(95 \% \mathrm{CIs})$. All P values were two sided, and a $\mathrm{P}$ value $<0.05$ was regarded as statistically significant.

\section{RESULTS}

\section{Characteristics of patients and controls}

The demographic and clinical characteristics of the study subjects are shown in Table 1. As expected, no significant difference was identified between the case and control subjects in terms of age or gender $(\mathrm{P}>0.05)$. The CAD cases were more likely to be cigarette smokers, have a history of hypertension, have a higher value of total cholesterol, triglycerides, and LDL-C, and have a lower value of HDL-C. No significant difference was identified in alcohol 
consumption between the case and control patients.

The genotype distributions of IL-6-174G/C, IL-6-572C/G, IL-10-1082A/G, and IL$10-819 \mathrm{C} / \mathrm{T}$ were in line with Hardy-Weinberg equilibrium in the control group (Table 2). However, the genotype distribution of IL- $1 \beta+3954 \mathrm{C} / \mathrm{T}$ was not. Moreover, we found that the minor allele frequencies of the five gene polymorphisms in the control group were similar to those in the Single Nucleotide Polymorphism Database (dbSNP).

Conditional logistic regression analyses showed that the CC genotype of IL-6-174G/C was significantly associated with increased risk of CAD when compared with the GG genotype, and the OR (95\%CI) was 2.99 (1.56-6.00) (Table 3). Moreover, the GG genotype of IL-6$572 \mathrm{C} / \mathrm{G}$ was correlated with increased risk of CAD when compared with the CC genotype, and the OR $(95 \% \mathrm{CI})$ was $1.99(1.25-3.19)$. However, we did not find significant association between IL-1 $\beta+3954 \mathrm{C} / \mathrm{T}$, IL-10-1082A/G, and IL-10-819C/T polymorphisms and risk of CAD.

Table 1. Demographic and clinical characteristics of study subjects.

\begin{tabular}{|c|c|c|c|c|c|c|}
\hline & CAD patients & $\%$ & Control subjects & $\%$ & $\chi^{2}$ or $t$-test & $P$ value \\
\hline \multicolumn{7}{|l|}{ Age } \\
\hline$<60$ & 196 & 53.8 & 201 & 55.2 & & \\
\hline$\geq 60$ & 169 & 46.2 & 164 & 44.8 & 0.14 & 0.71 \\
\hline \multicolumn{7}{|l|}{ Gender } \\
\hline Female & 141 & 38.7 & 153 & 41.8 & & \\
\hline Male & 224 & 61.3 & 212 & 58.2 & 0.82 & 0.37 \\
\hline \multicolumn{7}{|l|}{ Tobacco consumption } \\
\hline Never & 188 & 51.4 & 229 & 62.7 & & \\
\hline Sometimes & 177 & 48.6 & 136 & 37.3 & 9.40 & 0.002 \\
\hline \multicolumn{7}{|l|}{ Alcohol consumption } \\
\hline Never & 227 & 62.2 & 241 & 65.9 & & \\
\hline Sometimes & 138 & 37.8 & 124 & 34.1 & 1.17 & 0.28 \\
\hline \multicolumn{7}{|l|}{ Hypertension } \\
\hline No & 155 & 42.5 & 297 & 81.3 & & \\
\hline Yes & 210 & 57.5 & 68 & 18.7 & 117.14 & $<0.01$ \\
\hline Total cholesterol $(\mathrm{mg} / \mathrm{dL})$ & $193.6 \pm 38.6$ & & $161.4 \pm 25.7$ & & 13.27 & $<0.01$ \\
\hline Triglycerides (mg/dL) & $137.2 \pm 34.7$ & & $107.5 \pm 29.3$ & & 12.49 & $<0.01$ \\
\hline LDL-C $(\mathrm{mg} / \mathrm{dL})$ & $116.2 \pm 25.2$ & & $93.5 \pm 12.8$ & & 15.34 & $<0.01$ \\
\hline HDL-C (mg/dL) & $38.7 \pm 9.5$ & & $43.2 \pm 10.7$ & & 6.01 & $<0.01$ \\
\hline
\end{tabular}

$\mathrm{CAD}=$ coronary artery disease; LDL-C $=$ low-density lipoprotein cholesterol; HDL-C $=$ high-density lipoprotein cholesterol.

Table 2. Genotype characteristics of the five single nucleotide polymorphisms (SNPs) in the cases and controls.

\begin{tabular}{|c|c|c|c|c|c|}
\hline \multirow[t]{2}{*}{ Gene polymorphism } & \multirow[t]{2}{*}{ SNP } & \multirow[t]{2}{*}{ Alleles } & \multicolumn{2}{|c|}{ MAF } & \multirow[t]{2}{*}{ HWE (P value) in controls } \\
\hline & & & Control group & From dbSNP & \\
\hline IL-1 $\beta+3954 C / T$ & rs1143634 & $\mathrm{C} / \mathrm{T}$ & 0.160 & 0.146 & $<0.05$ \\
\hline IL-6-174G/C & rs 1800795 & $\mathrm{G} / \mathrm{C}$ & 0.186 & 0.185 & 0.39 \\
\hline IL-6-572C/G & rs1800796 & $\mathrm{C} / \mathrm{G}$ & 0.332 & 0.314 & 0.46 \\
\hline IL-10-1082A/G & rs1800896 & $\mathrm{A} / \mathrm{G}$ & 0.327 & 0.303 & 0.65 \\
\hline IL-10-819C/T & rs1800871 & $\mathrm{C} / \mathrm{T}$ & 0.400 & 0.409 & 0.07 \\
\hline
\end{tabular}

$\mathrm{MAF}=$ minor allele frequencies; HWE $=$ Hardy-Weinberg equilibrium; dbSNP = Single Nucleotide Polymorphism Database. 


\begin{tabular}{|c|c|c|c|c|c|c|c|}
\hline SNPs & & $\begin{array}{l}\text { CAD cases } \\
(\mathrm{N}=365)\end{array}$ & $\%$ & $\begin{array}{l}\text { Controls } \\
(\mathrm{N}=365)\end{array}$ & $\%$ & Adjusted OR $(95 \% \mathrm{CI})^{1}$ & $P$ value \\
\hline \multirow[t]{3}{*}{ IL- $1 \beta+3954 \mathrm{C} / \mathrm{T}$} & $\mathrm{CC}$ & 261 & 71.6 & 273 & 74.7 & 1.0 (Ref.) & - \\
\hline & $\mathrm{CT}$ & 74 & 20.2 & 68 & 18.6 & $1.14(0.77-1.68)$ & 0.49 \\
\hline & TT & 30 & 8.2 & 24 & 6.7 & $1.31(0.72-2.40)$ & 0.35 \\
\hline \multirow[t]{3}{*}{ IL-6-174G/C } & GG & 213 & 58.3 & 245 & 67.1 & 1.0 (Ref.) & - \\
\hline & GC & 113 & 30.9 & 105 & 28.7 & $1.24(0.88-1.73)$ & 0.2 \\
\hline & $\mathrm{CC}$ & 39 & 10.8 & 15 & 4.2 & $2.99(1.56-6.00)$ & 0.001 \\
\hline \multirow[t]{3}{*}{ IL-6-572C/G } & $\mathrm{CC}$ & 132 & 36.2 & 166 & 45.5 & 1.0 (Ref.) & - \\
\hline & $\mathrm{CG}$ & 165 & 45.3 & 155 & 42.6 & $1.34(0.96-1.86)$ & 0.07 \\
\hline & GG & 68 & 18.5 & 43 & 11.9 & $1.99(1.25-3.19)$ & 0.002 \\
\hline \multirow[t]{3}{*}{ IL-10-1082A/G } & AA & 151 & 41.3 & 167 & 45.8 & 1.0 (Ref.) & - \\
\hline & $\mathrm{AG}$ & 166 & 45.6 & 157 & 43.1 & $1.17(0.85-1.61)$ & 0.67 \\
\hline & GG & 48 & 13.1 & 41 & 11.1 & $1.29(0.79-2.14)$ & 0.28 \\
\hline \multirow{3}{*}{ IL-10-819C/T } & $\mathrm{CC}$ & 126 & 34.6 & 141 & 38.7 & 1.0 (Ref.) & - \\
\hline & $\mathrm{CT}$ & 162 & 44.5 & 155 & 42.6 & $1.17(0.83-1.64)$ & 0.35 \\
\hline & TT & 76 & 20.9 & 68 & 18.7 & $1.25(0.82-1.92)$ & 0.28 \\
\hline
\end{tabular}

${ }^{1}$ Adjusted for gender, age, tobacco consumption, hypertension, total cholesterol, triglycerides, low-density lipoprotein cholesterol, and high-density lipoprotein cholesterol $\mathrm{OR}=$ odds ratio; $95 \% \mathrm{CI}=95 \%$ confidence interval.

\section{DISCUSSION}

$\mathrm{CAD}$ is a complex and severe disease that greatly affects human health. Although age, tobacco consumption, hypertension, and higher body mass index are thought to contribute to the development of CAD, its real etiology is not well understood. In our study, we assessed the association between IL-1 $\beta+3954 \mathrm{C} / \mathrm{T}$, IL-6-174G/C, IL-6-572C/G, IL-10-1082A/G, and IL-10-819C/T gene polymorphisms and the risk of CAD. Our study found that the CC genotype of IL-6-174G/C and the GG genotype of IL-6-572C/G are associated with increased risk of $\mathrm{CAD}$, which suggests that they can predict the risk, and influence the development and pathogenesis of CAD.

Previous studies have shown that inflammation plays an important role in the development of CAD, and increasing evidence from animal studies has indicated that many cytokines are associated with increased risk of atherosclerosis (Hansson et al., 2005; Kleemann et al., 2008; Ulleryd et al., 2014). Many epidemiologic studies have observed that polymorphisms in the genes encoding interleukin-1 receptor antagonist, such as IL-6, IL-16, IL-17, IL-18, and IL-23, are associated with the development of CAD (Zhang et al., 2011; Huang et al., 2013; Opstad et al., 2011, 2013; Galimudi et al., 2014; He et al., 2014; Zhang et al., 2014).

The results of this study showed that IL-6-174G/C and IL-6-572C/G significantly increased the risk of $\mathrm{CAD}$, and this significant association still existed even after adjusting confounding variables. The IL-6 gene has a chromosomal locus of $7 \mathrm{p} 21$, is reported to be a multifunctional cytokine, and is produced by immune and many nonimmune cells. IL-6 plays an important role in mediating inflammatory and regular metabolism (Bowcock et al., 1988). Several studies have reported the association between IL-6-174G/C and IL-6-572C/G gene polymorphisms and the risk of CAD (Jang et al., 2008; Phulukdaree et al., 2013; Tong et al., 2013; Elsaid et al., 2014). Phulukdaree et al. (2013) reported that the presence of the IL-6$174 \mathrm{G}$ allele influences levels of IL-6 and increases the risk of CAD in South African Indians. Elsaid et al. (2014) reported that the G allele of IL-6-174G/C is significantly associated with hypertensive CAD. Jang et al. (2008) conducted a case-control study in a Korean population, 
and found that IL-6-572C/G gene polymorphism is associated with CAD. However, some studies reported inconsistent results. Tong et al. (2013) conducted a case-control study in a Chinese population, and did not find a significant association between IL-6-174G/C and IL-6$572 \mathrm{C} / \mathrm{G}$ gene polymorphisms and the risk of CAD. One previous meta-analysis study that included 19 studies reported that IL-6-174G/C and IL-6-572G/C polymorphisms are associated with increased risk of CAD (Yang et al., 2013). The inconsistent study results may be caused by discrepancies in ethnicity, sample size, control selection, and study design. Therefore, there is a definite requirement for further studies that clarify the association between IL-6 gene polymorphisms and the risk of CAD.

In summary, we found that IL-6-174G/C and IL-6-572C/G gene polymorphisms are associated with an increased risk of CAD. Owing to the limitations of our study, further welldesigned, large sample, and multicenter studies are definitely needed.

\section{Conflicts of interest}

The authors declare no conflict of interest.

\section{ACKNOWLEDGMENTS}

Research supported by the Science and Technology Projects of Henan Province (\#142102310109, \#122102310088, and \#132102310142). We thank Prof. Liu Zongfang and Li Lin for their help.

\section{REFERENCES}

Bowcock AM, Kidd JR, Lathrop GM, Daneshvar L, et al. (1988). The human "interferon-beta 2/hepatocyte stimulating factor/interleukin-6" gene: DNA polymorphism studies and localization to chromosome 7p21. Genomics 3: 8-16.

CARDIoGRAMplusC4D Consortium, Deloukas P, Kanoni S, Willenborg C, et al. (2013). Large-scale association analysis identifies new risk loci for coronary artery disease. Nat. Genet. 45: 25-33.

Cha E, Fu ZY, Ma YT, Zhu Q, et al. (2014). A novel polymorphism of the GP78 gene is associated with coronary artery disease in Han population in China. Lipids Health Dis. 13: 147.

Elsaid A, Abdel-Aziz AF, Elmougy R and Elwaseef AM (2014). Association of polymorphisms G(-174)C in IL-6 gene and G(-1082)A in IL-10 gene with traditional cardiovascular risk factors in patients with coronary artery disease. Indian J. Biochem. Biophys. 51: 282-292.

Foroughmand AM, Shahbazi Z, Galehdari H, Purmahdi Borujeni M, et al. (2014). Association of MEF2A gene polymorphisms with coronary artery disease. Iran Red Crescent Med. J. 16: e13533.

Galimudi RK, Spurthi MK, Padala C, Kumar KG, et al. (2014). Interleukin 6(-174G/C) variant and its circulating levels in coronary artery disease patients and their first degree relatives. Inflammation 37: 314-321.

Ghaffari MA, Askari Sede S, Rashtchizadeh N, Mohammadzadeh G, et al. (2014). Association of CRP gene polymorphism with CRP levels and Coronary Artery Disease in Type 2 Diabetes in Ahvaz, southwest of Iran. Bioimpacts 4: 133-139.

Hansson GK (2005). Inflammation, atherosclerosis, and coronary artery disease. N. Engl. J. Med. 352: 1685-1695.

Harismendy O, Notani D, Song X, Rahim NG, et al. (2011). 9p21 DNA variants associated with coronary artery disease impair interferon- $\gamma$ signalling response. Nature 470: 264-268.

He F, Teng X, Gu H, Liu H, et al. (2014). Interleukin-6 receptor rs7529229 T/C polymorphism is associated with left main coronary artery disease phenotype in a Chinese population. Int. J. Mol. Sci. 15: 5623-5633.

He J, Gu D, Wu X, Reynolds K, et al. (2005). Major causes of death among men and women in China. N. Engl. J. Med. 353: 1124-1134.

Huang H, Zeng Z, Zhang L, Liu R, et al. (2013). The association of interleukin-16 gene polymorphisms with susceptibility of coronary artery disease. Clin. Biochem. 46: 241-244.

Jang Y, Kim OY, Hyun YJ, Chae JS, et al. (2008). Interleukin-6-572C $>$ G polymorphism-association with inflammatory 
variables in Korean men with coronary artery disease. Transl. Res. 151: 154-161.

Kleemann R, Zadelaar S and Kooistra T (2008). Cytokines and atherosclerosis: a comprehensive review of studies in mice. Cardiovasc. Res. 79: 360-376.

Lian J, Fang P, Dai D, Ba Y, et al. (2014). Association between LGALS2 3279C >T and coronary artery disease: A casecontrol study and a meta-analysis. Biomed. Rep. 2: 879-885.

McPherson R and Davies RW (2012). Inflammation and coronary artery disease: insights from genetic studies. Can. J. Cardiol. 28: 662-666.

Opstad TB, Pettersen AÅ, Arnesen H and Seljeflot I (2011). Circulating levels of IL-18 are significantly influenced by the IL-18 $+183 \mathrm{~A} / \mathrm{G}$ polymorphism in coronary artery disease patients with diabetes type 2 and the metabolic syndrome: an observational study. Cardiovasc. Diabetol. 10: 110.

Opstad TB, Arnesen H, Pettersen A ̊ and Seljeflot I (2014). The MMP-9 -1562 C/T polymorphism in the presence of metabolic syndrome increases the risk of clinical events in patients with coronary artery disease. PLoS One 9: e106816.

Opstad TB, Pettersen AÅ, Arnesen H and Seljeflot I (2013). The co-existence of the IL-18+183 A/G and MMP-9 -1562 $\mathrm{C} / \mathrm{T}$ polymorphisms is associated with clinical events in coronary artery disease patients. PLoS One 8: e74498.

Phulukdaree A, Khan S, Ramkaran P, Govender R, et al. (2013). The interleukin-6 -147 g/c polymorphism is associated with increased risk of coronary artery disease in young South African Indian men. Metab. Syndr. Relat. Disord. 11: 205-209.

Roger VL, Go AS, Lloyd-Jones DM, Benjamin EJ, et al. (2012). Executive summary: heart disease and stroke statistics 2012 update: a report from the American Heart Association. Circulation 125: 188-197.

Tong Z, Li Q, Zhang J, Wei Y, et al. (2013). Association between interleukin 6 and interleukin 16 gene polymorphisms and coronary heart disease risk in a Chinese population. J. Int. Med. Res. 41: 1049-1056.

Ulleryd MA, Bernberg E, Yang LJ, Bergström GM, et al. (2014). Metoprolol reduces proinflammatory cytokines and atherosclerosis in ApoE-/- mice. Biomed. Res. Int. 2014: 548783.

Yang Y, Zhang F, Skrip L, Lei H, et al. (2013). IL-6 gene polymorphisms and CAD risk: a meta-analysis. Mol. Biol. Rep. 40: 2589-2598.

Zhang M, Cai ZR, Zhang B, Cai X, et al. (2014). Functional polymorphisms in interleukin-23 receptor and susceptibility to coronary artery disease. DNA Cell Biol. 33: 891-897.

Zhang X, Pei F, Zhang M, Yan C, et al. (2011). Interleukin-17A gene variants and risk of coronary artery disease: a large angiography-based study. Clin. Chim. Acta. 412: 327-331. 